Research Article

\title{
Perceived Stress and Its Associated Factors during COVID-19 among Healthcare Providers in Ethiopia: A Cross-Sectional Study
}

\author{
Yigrem Ali Chekole $\mathbb{D}^{1},{ }^{1}$ Solomon Yimer Minaye, ${ }^{1}$ Semagn Mekonnen Abate, ${ }^{2}$ \\ and Birhanie Mekuriaw ${ }^{1}$ \\ ${ }^{1}$ Department of Psychiatry, College of Health Science and Medicine, Dilla University, Dilla, Ethiopia \\ ${ }^{2}$ Department of Anaesthesia, College of Health Science and Medicine, Dilla University, Dilla, Ethiopia \\ Correspondence should be addressed to Yigrem Ali Chekole; alyigrem@gmail.com
}

Received 24 May 2020; Revised 4 August 2020; Accepted 27 August 2020; Published 24 September 2020

Academic Editor: Giuseppe La Torre

Copyright (c) 2020 Yigrem Ali Chekole et al. This is an open access article distributed under the Creative Commons Attribution License, which permits unrestricted use, distribution, and reproduction in any medium, provided the original work is properly cited.

\begin{abstract}
Background. Coronavirus causes serious health problems worldwide including increased mental health burden to the society at large scale and particularly the healthcare providers. Understanding the immediate mental health and psychological response of the healthcare providers after a public health emergency is important for implementing better prevention and response mechanisms to a disaster. Objective. This study aimed to assess the prevalence of perceived stress and risk factors of coronavirus disease 2019 among healthcare providers in Dilla, Southern Ethiopia. Methods. An institution-based cross-sectional study was conducted among 244 samples selected with the systematic random sampling technique from March to April 2020. Data collection was carried out with a validated perceived stress scale adapted from the World Health Organization. Data were coded and entered into Epi Info Version 7 and were exported and analyzed with SPSS version 20. Crude and adjusted OR were analyzed using logistic regression, and the level of significance of association was determined at $P$ value $<0.05$. Result. The prevalence of perceived stress among participants was 126 (51.6\%). Being at the age range of $25-31$ years (AOR $=2.5,95 \% \mathrm{CI}, 1.12,5.81$ ), master's and above in their qualification $(\mathrm{AOR}=6.0,95 \% \mathrm{CI} 1.59,22.31)$, nurse professionals ( $\mathrm{AOR}=8.2,95 \% \mathrm{CI} 2.69,24.74)$, and pharmacist professionals ( $\mathrm{AOR}=4.8,95 \% \mathrm{CI}, 1.25,18.64$ ) were variables found to have a strong statistically significant association with the perceived stress of coronavirus disease. Conclusion. More than half of the study participants were found to have perceived stress for coronavirus disease. Early screening and intervention of stress among frontline healthcare providers based on the findings are suggested.
\end{abstract}

\section{Introduction}

Coronavirus disease 2019 (COVID-19) is a mild-to-severe respiratory illness that is caused by a coronavirus (genus: Betacoronavirus), is transmitted chiefly by contact with infectious material (such as respiratory droplets), and is characterized, especially, by fever, cough, and shortness of breath and may progress to pneumonia and respiratory failure $[1,2]$. Coronavirus disease (COVID-19) is a new strain that was first discovered in 2019 in Wuhan, China, and has not been previously identified in humans $[3,4]$. It is distinct from SARS, MERS, and influenza $[5,6]$. In the past two decades, more than 10, 000 cumulative cases, with mortality rates of $10 \%$ for SARS-CoV and $37 \%$ for MERS$\mathrm{CoV}$, happened worldwide [7-10].

The WHO declared COVID-19 a pandemic on March 11, 2020. Currently, COVID-19 has infected more than 18 million cases and claimed the lives of more than 600,000 people worldwide [11-13].

The first COVID-19 case confirmed in Addis Ababa, Ethiopia, was on March 31, 2020. The recent COVID-19 cases are around 43, and 2 deaths were reported $[12,14]$.

Due to the widespread disruptive effects of COVID-19, different countries have been taking different prevention and control measures such as quarantining, closing and suspension of transportations, avoiding public gatherings, and 
even holding different public service works including education. Because of the abovementioned measures, students, workers, tourists, and others have now been prevented from accessing their training institutions, workplaces, and home $[15,16]$.

Psychological symptoms such as anxiety/stress, panic buying, fear and paranoia about attending community events, and reduced autonomy and concerns about income, job, security, and so on have already been observed in a population. Being at home can place children at an increased risk of, or increased exposure to, child protection incidents or make them witness to interpersonal violence if their home is not a safe place [17]. Coronavirus pandemic fears prompt the government to activate emergency response and extend travel ban [17].

In addition to the community members, healthcare providers are also at risk of higher psychological distress due to longer working hours and high risk of exposure to the virus. This may also lead to stress, anxiety, burnout, depressive symptoms, and the need for sick or stress leave, which would harm the capacity of the health system to provide services during the crisis [18]. Even though the psychological impact of the coronavirus disease (COVID19) pandemic must be recognized alongside the physical symptoms, the global response is a simple public health strategy such as hand washing, quarantine, and social distancing [12, 19]. If left untreated, these psychological symptoms may have long-term health effects health workers and require treatment adding to the cost burden of managing the illness [20,21].

To date, the Ethiopian government's focus has been on managing the medical needs of people during the pandemic, rather than providing resources to meet short- and longterm mental health implications. So, this paper aims to assess the psychological burdens of COVID-19 and recommended possible mitigating strategies. Therefore, it is vital to assess the magnitude of perceived stress and risk factors of coronavirus disease 2019 among healthcare providers in Dilla, Southern Ethiopia, 2020.

\section{Methods and Materials}

2.1. Study Design, Period, Setting, and Population. The institution-based cross-sectional study design was conducted from March to April 2020 among healthcare providers of governmental health institutions in Dilla Town, which is found in the Gedeo Zone on the main road from Addis Ababa to Kenya, $360 \mathrm{~km}$ south of Addis Ababa and $90 \mathrm{~km}$ south of Hawassa (capital of SNNPR) and has a longitude and latitude of $6^{0} 24^{\prime} 30^{\prime \prime} \mathrm{N} 38^{\circ} 18^{\prime} 30^{\prime \prime} \mathrm{E}$ with an elevation of 1570 meters above sea level. There are four governmental health institutions in the study area, one of which is Dilla University referral hospital, while the others are health centers. There are about five hundred and fifty healthcare providers. The study population was healthcare providers who were working in governmental health institutions of Dilla town during the study period. All healthcare providers who were seriously ill and unable to communicate were not included in the study.
2.2. Sample Size and the Sampling Technique. The sample size (n) was calculated based on a single population proportion formula, by assuming 95\% confidence level, and the prevalence of perceived stress of COVID-19 among healthcare providers was not known, Therefore, a proportion of $50 \%$, $95 \%$ confidence interval, and margin of error $(d)=5 \%$ were taken:

$$
\begin{aligned}
& n=\frac{(Z \alpha / 2)^{2} \times p(1-p)}{d^{2}} \\
& n=\frac{(1.96)^{2} \times 0.50(1-0.5)}{0.05^{2}}=384 .
\end{aligned}
$$

Since the source population is less than 10,000 , the reduction formula was employed, giving a sample size of 244 with a $10 \%$ nonresponse rate. We used a systematic sampling technique with the proportion allocation system among each health center and one referral hospital based on the total number of healthcare providers in each institutions.

2.3. Data Collection Procedures and Instrument. A structured questionnaire adapted from WHO validated for perceived stress was used to collect the data. The questionnaire contained sociodemographic characteristics (age, sex, profession, qualification, income, religion, marital status, ethnicity, and work experience). Data on perceived stress were collected with a perceived stress scale (PSS-10) which is a 10item scale. The tool has a 5-point Likert response. Each item was scored with $0=$ Never, $1=$ Almost Never, $2=$ Sometimes, 3 = Fairly Often, and $4=$ Very Often, which was employed to evaluate each item. The total score ranged from 0 to 40 [22]. The reliability of PSS-10 was very high ranging from 0.71 to 0.86 , which was validated in different settings, languages, and population [22-26].

2.4. Data Quality Assurance. The pretest was conducted on $5 \%$ of the sample size. The training was given to the data collectors and supervisors on the data collection tool and sampling techniques. Supervision was held regularly during the data collection period by the researcher, coinvestigators, and supervisors. The data were cross checked for completeness and consistency daily.

2.5. Statistical Analysis and Processing. Data were entered into Epi Info version 7 computer programs and transported to SPSS version 22 computer program for further analysis and cleaning. Descriptive statistics was used to summarize tables and figures, and statistical summary measures were used for presentation. The association of perceived stressrelated variables and demographic characteristics were analyzed using chi-square, fisher's exact test, and binary logistic regression with odds ratio and 95\% CI in the univariate analysis. Multivariate logistic regression analysis was carried out to find the association of each independent variable with the outcome variable. The model was checked for fitness with the $R$-squared value, where an $R$-squared value greater than $50 \%$ was considered as good. All variables with a $P$ 
value $<0.20$ in the univariate analysis were entered into the multivariate logistic regression model. Odds ratios (OR) and 95\% confidence intervals were calculated. A $P$ value of less than 0.05 was considered significant.

2.6. Ethical Clearance. Ethical clearance was obtained from the Institutional Review Board of Dilla University and Gedeo Zone health bureau. The purpose and importance of the study were explained to each participant before they proceed into actual activities. Confidentiality was maintained by an anonymous questionnaire, and informed consent was obtained from each participant.

\section{Result}

3.1. Sociodemographic Characteristics of the Respondents. A total of 244 participants were included in the study with a response rate of $100 \%$. Among the respondents, the majority were males $(161(66 \%))$, while the majority of the respondents were in the age range of $25-31$ years (162 (66.4\%)). Of the total participants, $124(50.8 \%)$ of them were protestant religion followers, and 76 (31.1\%) were Amhara in their ethnicity. The majority of the participants were single 140 (57.4\%)

The qualification of participants indicated that 158 $(64.8 \%)$ of them were degree level regarding their profession, and $100(41.0 \%)$ of the participants were nurses. The majority of the respondents 130 (53.3) had working experiences in the range of 1-5 years, and the majority of the respondents' (96 (39.3\%)) monthly income was ranging from 3000 to 5000 Ethiopian Birr (Table 1).

3.2. Perceived Stress of the Respondents. The majority of the respondents were very annoyed by things that happened outside very often, while some others felt well fairly often. On the other hand, the majority of the respondents were able to complete the important events in their life properly, while others could not cope with all the things happening outside (Table 2).

Perceived stress, among healthcare providers, was very high. The highest perceived stress score was observed among nurses, sixty-eight from hundred, while the smallest was seen among anaesthetists and other healthcare providers (three from ten and three from twelve), respectively (Figure 1).

The magnitude of perceived stress on COVID-19 among healthcare providers in Dilla town in Dilla, Southern Ethiopia, 2020.

The prevalence of perceived stress on COVID-19 among participants was found to be 126 (51.6\%), with the respondents in the last month of their life.

Risk factors of perceived stress on COVID-19 among healthcare providers in Dilla town.

In bivariate, binary logistic analysis variables, sex, age, marital status, monthly income, qualification, profession, and work experiences, were found to have a $P$ value less than 0.25 . These variables fulfilled minimum requirements for further multivariate binary logistic regression.
TABLE 1: Sociodemographic characteristics of respondents in Dilla town government health institutions, Dilla, Southern Ethiopia, 2020.

\begin{tabular}{|c|c|c|c|}
\hline Variable & Categories & Frequency & $\begin{array}{c}\text { Percentage } \\
(\%)\end{array}$ \\
\hline \multirow{2}{*}{ Sex } & Female & 83 & 34.00 \\
\hline & Male & 161 & 66.00 \\
\hline \multirow{3}{*}{ Age } & $18-24$ & 48 & 19.7 \\
\hline & $25-31$ & 162 & 66.4 \\
\hline & $>31$ & 34 & 13.9 \\
\hline \multirow{3}{*}{ Marital status } & Single & 140 & 57.4 \\
\hline & Married & 90 & 36.9 \\
\hline & Divorced/widowed & 14 & 5.7 \\
\hline \multirow{4}{*}{ Religion } & Orthodox & 100 & 41.0 \\
\hline & Muslim & 16 & 6.6 \\
\hline & Protestant & 124 & 50.8 \\
\hline & Catholic & 4 & 1.6 \\
\hline \multirow{5}{*}{ Ethnicity } & Gedeo & 72 & 29.5 \\
\hline & Oromo & 36 & 14.5 \\
\hline & Amhara & 76 & 31.1 \\
\hline & Gurage & 20 & 8.2 \\
\hline & Others* & 40 & 16.4 \\
\hline \multirow{4}{*}{ Monthly income } & $<3000$ & 50 & 20.5 \\
\hline & $3000-5000$ & 96 & 39.3 \\
\hline & $5000-7000$ & 50 & 20.5 \\
\hline & $>7000$ & 48 & 19.7 \\
\hline \multirow{3}{*}{ Qualification } & Diploma & 66 & 27.0 \\
\hline & Degree & 158 & 64.8 \\
\hline & Master's and above & 20 & 8.2 \\
\hline \multirow{7}{*}{ Profession } & Medical doctor & 27 & 11.1 \\
\hline & Nurse & 100 & 41.0 \\
\hline & Health officer & 15 & 6.1 \\
\hline & Midwifery & 24 & 9.8 \\
\hline & $\begin{array}{l}\text { Laboratory } \\
\text { technology }\end{array}$ & 24 & 9.8 \\
\hline & Pharmacist & 23 & 9.4 \\
\hline & Others** & 31 & 12.7 \\
\hline \multirow{3}{*}{$\begin{array}{l}\text { Work } \\
\text { experience }\end{array}$} & $<1$ year & 50 & 20.5 \\
\hline & $1-5$ years & 130 & 53.3 \\
\hline & $>5$ years & 64 & 26.2 \\
\hline
\end{tabular}

${ }^{*}$ Others = Tigray, Kembata, Siltie, and Sidama; ${ }^{* *}$ others = anesthesia, environmental health, health education, occupational health, and psychiatry.

From multivariate binary logistic regression, only variables, namely, age in the range of 25-31 years, being a nurse, and being pharmacist, were statistically significant with perceived stress on COVID-19 at a $P$ value less than 0.05 .

The odds of having perceived stress on COVID-19 among respondents who were in the age range of 25-31 years was almost 3 times higher as compared to that in the age range of $18-24$ years of respondents $(\mathrm{AOR}=2.5,95 \% \mathrm{CI}$, $1.12,5.81)$. On the other hand, participants who are master's and above in their qualification were 6 times more likely to have perceived stress during COVID-19 as compared with those who are diploma in their qualification $(\mathrm{AOR}=6.0$, 95\% CI, 1.59, 22.31).

In this study, participants who are nurses in their profession were almost 8 times more likely to have perceived stress on COVID-19 as compared with respondents who are doctors $(\mathrm{AOR}=8.2,95 \% \mathrm{CI} 2.69,24.74)$. 


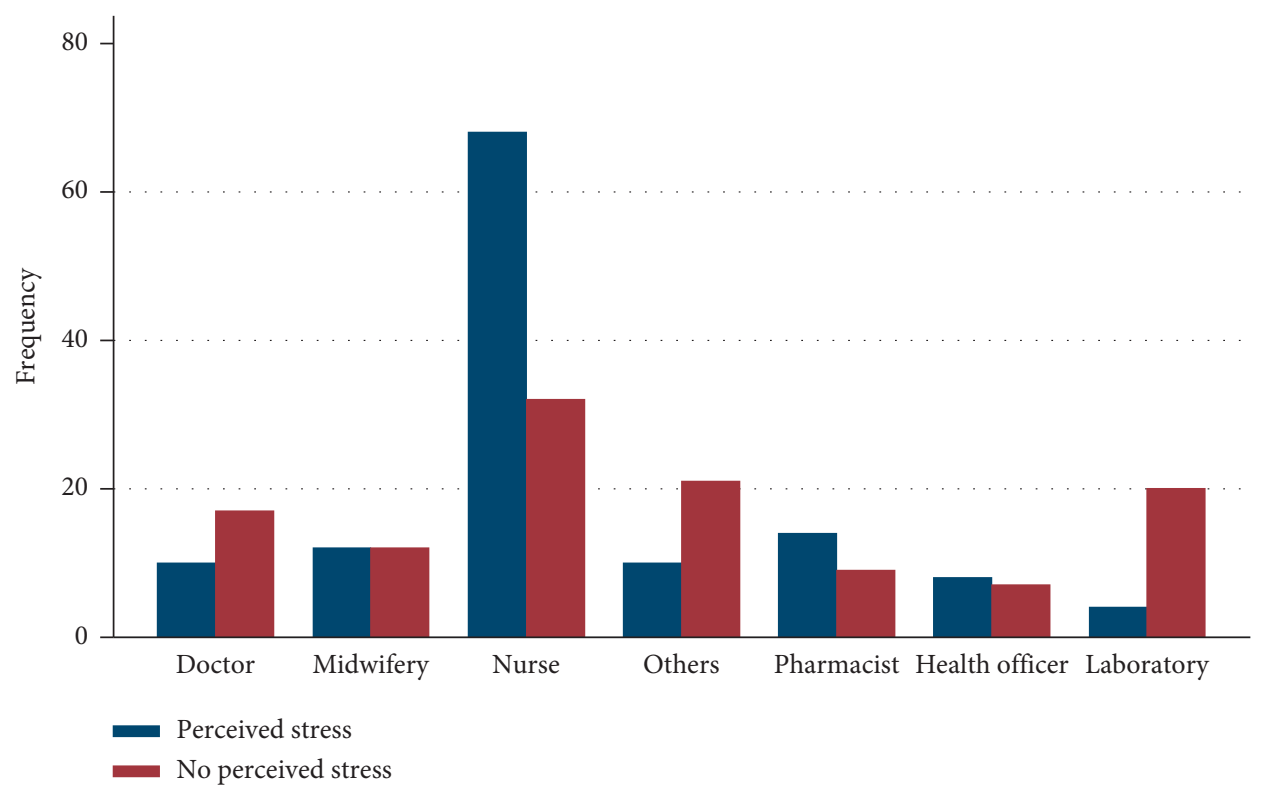

FIgURE 1: Perceived stress among healthcare providers of Dilla governmental health institutions, Southern Ethiopia, 2020.

TABLe 2: Perceived Stress Scale (PSS) among healthcare providers in Dilla town in Dilla, Southern Ethiopia, 2020.

\begin{tabular}{|c|c|c|c|c|c|c|}
\hline Items & Never & Almost never & Sometimes & Fairly often & Very often & Total \\
\hline Something unexpectedly & $52(21 \%)$ & $32(13 \%)$ & $70(29 \%)$ & $54(22 \%)$ & $36(15 \%)$ & 244 \\
\hline Unable to control the important things in life & $62(25 \%)$ & $40(16 \%)$ & $66(27 \%)$ & $56(23 \%)$ & $20(8 \%)$ & 244 \\
\hline Felt nervous and stressed & $46(19 \%)$ & $42(17 \%)$ & $68(29 \%)$ & $58(24 \%)$ & $30(12 \%)$ & 244 \\
\hline Felt confident about your ability to handle your problems & $44(18 \%)$ & $42(17 \%)$ & $72(30 \%)$ & $58(24 \%)$ & $28(11 \%)$ & 244 \\
\hline Felt that things were going your way & $34(14 \%)$ & $30(12 \%)$ & $76(31 \%)$ & $76(31 \%)$ & $28(11 \%)$ & 244 \\
\hline Could not cope with all the things & $44(18 \%)$ & $56(23 \%)$ & $74(30 \%)$ & $52(21 \%)$ & $18(7 \%)$ & 244 \\
\hline Able to control irritations in life & $38(16 \%)$ & $28(11 \%)$ & $68(29 \%)$ & $72(30 \%)$ & $38(16 \%)$ & 244 \\
\hline Felt on top of things & $32(13 \%)$ & $42(17 \%)$ & $54(22 \%)$ & $88(36 \&)$ & $28(11 \%)$ & 244 \\
\hline Angered by things outside & $32(13 \%)$ & $42(17 \%)$ & $70(29 \%)$ & $58(24 \%)$ & $42(17 \%)$ & 244 \\
\hline Felt difficulties and could not overcome & $48(20 \&)$ & $44(18 \%)$ & $64(26 \%)$ & $62(25 \%)$ & $26(11 \%)$ & 244 \\
\hline
\end{tabular}

Participants who are pharmacists were also another factor associated with perceived stress on COVID-19. Participants who were pharmacists in their profession were 5 times more likely to have perceived stress on COVID-19 as compared with respondents who are medical doctors $(\mathrm{AOR}=4.895 \% \mathrm{CI}, 1.25,18.64)$ (Table 3$)$.

\section{Discussion}

This cross-sectional study had tried to determine the magnitude of perceived stress and associated risk factors among healthcare providers of Gedeo Zone governmental health institutions on COVID-19 using a perceived stress scale (PSS-10).

The majority of healthcare providers were predominantly males $(161(66.0 \%))$. The overall prevalence of perceived stress among healthcare providers of Gedeo Zone governmental health institutions was found to be $51.6 \%$. The finding of this study was in line with the study conducted in China by Wang et al. (53.8\%) [27]. On the other hand, the findings of a study conducted in Wuhan, China, by Dai et al. were lower as compared to those of this study $(39.1 \%$ vs. $51.6 \%$ ) [28]. The possible explanation might be due to the sampling size, sampling technique (convenience sampling), and different tools, while they used a general health questionnaire (GHQ-12).

In this study, the majority of the respondents were males $(161(66.0 \%))$, in the age range of $25-31$ years (162 $(66.4 \%))$ and single $(140(57.4 \%))$. On the contrary, a study conducted in China revealed that the majority of respondents were female $(67.3 \%)$, in the age range of 21.4 to 30.8 years $(53.1 \%)$ and married $(76.4 \%)$ [27]. The possible explanation for this difference might be due to the development of the country; the developed country involved women and marriage at a proper age due to the economic status of the people.

This study revealed that the majority of the respondents were nurses $(100(41.0 \%))$. This finding was consistent with that of other studies conducted in China (2,343 (53.8\%) [28] and $764(60.8 \%)$ [29]). However, this study showed that the majority of healthcare providers' work experience was one to five years $130(53.3 \%)$ unlike that in a study conducted in 
TABLE 3: Bivariate and multivariate analysis of factors associated with perceived stress on COVID-19 among healthcare providers in Dilla town, Southern Ethiopia, 2020.

\begin{tabular}{|c|c|c|c|c|c|}
\hline \multicolumn{2}{|c|}{ Variables } & \multicolumn{2}{|c|}{ Perceived stress } & \multirow{2}{*}{ COR $(95 \% \mathrm{CI})$} & \multirow{2}{*}{ AOR $(95 \% \mathrm{CI})$} \\
\hline & & Yes & No & & \\
\hline \multirow{2}{*}{ Sex of participants } & Female & 44 & 39 & $1.1(0.64-1.85)$ & $0.9(0.47-1.67)$ \\
\hline & Male & 82 & 79 & 1 & 1 \\
\hline \multirow{3}{*}{ Age } & $18-24$ & 16 & 32 & 1 & 1 \\
\hline & $25-31$ & 91 & 71 & $2.6(1.3-5.04)$ & $2.5(1.12-5.81)^{*}$ \\
\hline & $>31$ & 19 & 15 & $2.5(1.02-6.26)$ & $1.7(0.53-5.21)$ \\
\hline \multirow{3}{*}{ Marital status } & Single & 68 & 72 & 1 & 1 \\
\hline & Married & 48 & 42 & $1.2(0.71-2.06)$ & $1.0(0.49-2.05)$ \\
\hline & Divorced/widowed & 10 & 4 & $2.7(0.79-8.84)$ & $2.7(0.65-11.02)$ \\
\hline \multirow{3}{*}{ Qualification } & Diploma & 33 & 33 & 1 & 1 \\
\hline & Degree & 82 & 76 & $1.1(0.61-1.92)$ & $1.6(0.77-3.20)$ \\
\hline & Master's and above & 11 & 9 & $1.2(0.45-3.34)$ & $6.0(1.59-22.31)^{* *}$ \\
\hline \multirow{7}{*}{ Profession of participants } & Medical doctor & 10 & 17 & $1.2(0.42-3.66)$ & $1.3(0.35-4.69)$ \\
\hline & Nurses & 68 & 32 & $4.5(1.88-10.57)$ & $8.2(2.69-24.74)^{* *}$ \\
\hline & Health officer & 8 & 7 & $2.4(0.68-8.49)$ & $3.2(0.74-13.46)$ \\
\hline & Midwifery & 12 & 12 & $2.1(0.70-6.30)$ & $3.5(0.92-13.16)$ \\
\hline & Laboratory & 4 & 20 & $0.4(0.11-1.56)$ & $0.4(0.10-1.88)$ \\
\hline & Pharmacist & 14 & 9 & $3.3(1.06-10.07)$ & $4.8(1.25-18.64)^{*}$ \\
\hline & Others $^{\mathrm{a}}$ & 10 & 21 & 1 & 1 \\
\hline \multirow{3}{*}{ Work experience } & $<1$ year & 20 & 30 & $0.4(0.20-0.91)$ & $0.9(0.30-2.53)$ \\
\hline & $1-5$ years & 67 & 63 & $0.7(0.37-1.25)$ & $0.7(0.32-1.56)$ \\
\hline & $>5$ years & 39 & 25 & 1 & 1 \\
\hline
\end{tabular}

${ }^{*} P$ value is significant at $P<0.05 ;{ }^{* *} P$ value is significant at $P<0.01$; others ${ }^{\mathrm{a}}=$ anesthesia, environmental health, health education, occupational health, and psychiatry.

China which was six to ten years (1960 (45\%) [28]). This discrepancy might be due to differences in the educational development system, economical status, sample size, and work experience rubrics.

The study revealed that age and profession were independent predictors of perceived stress. The odds of having perceived stress on COVID-19 among respondents who were in the age range of 25-31 years was 3 times more likely as compared to that in the age range of 18-24 years of respondents.

On the other hand, this study showed that participants who were nurses in their profession were 8 times more likely to have perceived stress on COVID-19 as compared to respondents who were doctors. This finding is in line with a study conducted in China on perceived stress on COVID-19 among healthcare workers [28]. The possible explanation might be nurses being frontline healthcare workers, directly engaged in diagnosis, treatment, and care of patients with COVID-19, and they are more as compared with other professions.

Participants who are pharmacists were also another factor associated with perceived stress on COVID-19. Participants who were pharmacists in their profession were 4 times more likely to have perceived stress on COVID-19 as compared with respondents who were doctors. The pharmacists are also involved directly in providing drugs for patients with COVID-19, and they are at high risk.

On the other hand, participants who were master's and above in their qualification were 6 times more likely to have perceived stress during COVID-19 as compared with diploma in their qualification. This might be due to the fact that they conducted and explored different types of scientific researches about the virulent nature of the COVID-19 pandemic.

4.1. Limitations. The study was limited to assess barriers of preexisting mental illness and chronic medical condition.

\section{Conclusions}

In summary, this study revealed that more than half of healthcare providers were found to have perceived stress on COVID-19. Being at the age range of 25-31 years, master's and above in their qualification, nurse professionals, and pharmacist professionals were variables found to have a statistically significant association with perceived stress on COVID-19. Particularly, of great concern should be given to healthcare workers because they are at great risk of developing psychological problems. So, the findings suggest that routine screening of psychological problems and early intervention is highly recommended.

\section{Abbreviations}

AOR: $\quad$ Adjust odds ratio

CI: $\quad$ Confidence interval

COVID-19: Coronavirus disease 19

COR: $\quad$ Crude odds ratio

DU: Dilla University

Epi Info: Epidemiological information 
GHQ: General health questionnaire

HCWs: Healthcare workers

MERS: $\quad$ Middle East respiratory syndrome

SARS: $\quad$ Severe acute respiratory syndrome

SNNPR: Southern Nations, Nationalities, and Peoples' Region

SPSS: $\quad$ Statistical Package for Social Science

PSS: $\quad$ Perceived stress scale

WHO: World Health Organization.

\section{Data Availability}

The data used to support the findings of this study are available from the corresponding author upon request.

\section{Ethical Approval}

Ethical clearance was obtained from the Institutional Review Board (IRB) of Dilla University.

\section{Consent}

Written consent was obtained from each participant during data collection. All participants were well informed about the aims and purpose of the study, and those participants were informed that as the right is given to the study participants to refuse and stop or withdraw from participation at any time during data collection without loss of any entitlement.

\section{Conflicts of Interest}

The authors declare that there are no conflicts of interest.

\section{Authors' Contributions}

YA and SM conceived the research question, involved in data collection, analysis, and interpretation, and critically reviewed the manuscript. SY and BM participated during the proposal development, analysis, and interpretation of the data and contributed to manuscript preparation. All the authors read and approved the final manuscript.

\section{Acknowledgments}

The authors thank the study participants for investing their fruitful time in participating in the study.

\section{References}

[1] I. Merriam-Webster, Merriam-Webster's Dictionary of Synonyms, Merriam-Webster, Springfield, MA, USA, 1984.

[2] M.-W. Staff, Merriam-Webster's Collegiate Dictionary, Merriam-Webster, Springfield, MA, USA, 2004.

[3] Z. Zhu, S. Xu, H. Wang, Z. Liu, J. Wu, and G. Li, COVID-19 in Wuhan: Immediate Psychological Impact on 5062 Health Workers, MedRxiv, 2020.

[4] C.-C. Lai, T.-P. Shih, W.-C. Ko, H.-J. Tang, and P.-R. Hsueh, "Severe acute respiratory syndrome coronavirus 2 (SARSCoV-2) and coronavirus disease-2019 (COVID-19): the epidemic and the challenges," International Journal of Antimicrobial Agents, vol. 55, no. 3, Article ID 105924, 2020.

[5] I.-C. Huang, C. C. Bailey, J. L. Weyer, S. R. Radoshitzky, M. M. Becker, and J. J. Chiang, "Distinct patterns of IFITMmediated restriction of filoviruses, SARS coronavirus, and influenza A virus," PLoS Pathogens, vol. 7, no. 1, 2011.

[6] N. Liu, F. Zhang, C. Wei et al., "Prevalence and predictors of PTSS during COVID-19 outbreak in China hardest-hit areas: gender differences matter," Psychiatry Research, vol. 287, Article ID 112921, 2020.

[7] M. J. Kern, Global Epidemics, Pandemics, Terrorism: Risk Assessment and European Responses, ISPSW Strategy Series: Focus on Defense and International Security, Zürich, Switzerland, 2016.

[8] H. Shiqin, Viral Respiratory Infections in Singapore, ScholarBank@NUS Repository, Singapore, 2015.

[9] F. Nicholson, "Infectious Diseases: the Role of the Healthcare Professional," in Clinical Forensic Medicine, pp. 343-392, Springer, Berlin, Germany, 2020.

[10] L.-F. Wang and D. E. Anderson, "Viruses in bats and potential spillover to animals and humans," Current Opinion in Virology, vol. 34, pp. 79-89, 2019.

[11] World Health Organization, Critical Preparedness, Readiness and Response Actions for COVID-19: Interim Guidance, 22 March 2020, World Health Organization, Geneva, Switzerland, 2020.

[12] M. Gilbert, G. Pullano, F. Pinotti et al., "Preparedness and vulnerability of African countries against importations of COVID-19: a modelling study," The Lancet, vol. 395, no. 10227, pp. 871-877, 2020.

[13] M. Gilbert, G. Pullano, F. Pinotti, E. Valdano, C. Poletto, and P.-Y. Boelle, Preparedness and Vulnerability of African Countries against Introductions of 2019-nCoV, medRxiv, 2020.

[14] World Health Organization, Coronavirus Disease 2019 (COVID-19): Situation Report, World Health Organization, Geneva, Switzerland, 2020.

[15] N. Khan and S. Faisal, "Epidemiology of Coronavirus in the world and its effects on the China economy," SSRN Electronic Journal, 2020.

[16] S. Barua, "Understanding Coronanomics: the economic implications of the coronavirus (COVID-19) pandemic," SSRN Electronic Journal, 2020.

[17] X. Zhou, C. L. Snoswell, L. E. Harding et al., "The role of telehealth in reducing the mental health burden from COVID-19," Telemedicine and E-Health, vol. 26, no. 4, pp. 377-379, 2020.

[18] E. M. J. Smith, "Ethnic minorities," The Counseling Psychologist, vol. 13, no. 4, pp. 537-579, 1985.

[19] F. Thienemann, F. Pinto, D. E. Grobbee et al., "World heart federation briefing on prevention: coronavirus disease 2019 (COVID-19) in low-income countries," Global Heart, vol. 15, no. 1, p. $23,2020$.

[20] X. Kong, K. Zheng, M. Tang, F. Kong, J. Zhou, and L. Diao, Prevalence and Factors Associated with Depression and Anxiety of Hospitalized Patients with COVID-19, medRxiv, 2020.

[21] O. Home, I. S. Series, and S. Plan, Bridging Science and Service: A Report by the National Advisory Mental Health Council's Clinical Treatment and Services Research Workgroup, National Institutes of Health (NIH), Bethesda, MD, USA, 1999.

[22] M. Chaaya, H. Osman, G. Naassan, and Z. Mahfoud, "Validation of the Arabic version of the cohen perceived stress scale (PSS-10) among pregnant and postpartum women," BMC Psychiatry, vol. 10, no. 1, p. 111, 2010. 
[23] M. Hattar-Pollara and H. Dawani, "Cognitive appraisal of stress and health status of wage working and nonwage working women in Jordan," Journal of Transcultural Nursing, vol. 17, no. 4, pp. 349-356, 2006.

[24] F. Bastani, A. Hidarnia, A. Kazemnejad, M. Vafaei, and M. Kashanian, "A randomized controlled trial of the effects of applied relaxation training on reducing anxiety and perceived stress in pregnant women," Journal of Midwifery \& Women's Health, vol. 50, no. 4, pp. e36-e40, 2005.

[25] S.-Y. Wang and C.-H. Chen, "Psychosocial health of Taiwanese postnatal husbands and wives," Journal of Psychosomatic Research, vol. 60, no. 3, pp. 303-307, 2006.

[26] F.-H. Chou, K. C. Avant, S.-H. Kuo, and S. J. Fetzer, "Relationships between nausea and vomiting, perceived stress, social support, pregnancy planning, and psychosocial adaptation in a sample of mothers: a questionnaire survey," International Journal of Nursing Studies, vol. 45, no. 8, pp. 1185-1191, 2008.

[27] C. Wang, R. Pan, X. Wan et al., "Immediate psychological responses and associated factors during the initial stage of the 2019 coronavirus disease (COVID-19) epidemic among the general population in China," International Journal of Environmental Research and Public Health, vol. 17, no. 5, p. 1729, 2020.

[28] Y. Dai, G. Hu, H. Xiong, H. Qiu, and X. Yuan, Psychological Impact of the Coronavirus Disease 2019 (COVID-19) Outbreak on Healthcare Workers in China, MedRxiv, 2020.

[29] J. Lai, S. Ma, Y. Wang, Z. Cai, J. Hu, and N. Wei, "Factors associated with mental health outcomes among healthcare workers exposed to Coronavirus disease 2019," Journal of the American Medical Association Network Open, vol. 3, no. 3, Article ID e203976, 2020. 